\title{
EL NUEVO COMUNISMO LACANIANO
}

\section{NEW LACANIAN COMMUNISM}

\author{
Roy Alfaro Vargas*
}

\section{RESUMEN}

Este artículo analiza, dentro del contexto de la actual crisis sistémica y financiera del capitalismo y la profundización del neoliberalismo, la propuesta de varios autores (Bosteels, Dean, Badiou y Žižek) en relación con la idea de un comunismo ligado a lo Real lacaniano, la cual que se ha denominado el nuevo comunismo lacaniano. Se plantea que este nuevo comunismo lacaniano evade los problemas derivados de la crisis actual y de la consecuente exacerbación del neoliberalismo y por consiguiente, se aleja de la posición marxista con la cual pretende estar asociada. En síntesis, el nuevo comunismo lacaniano se manifiesta como un nuevo idealismo filosófico, que niega la acción política contestataria y el cambio social.

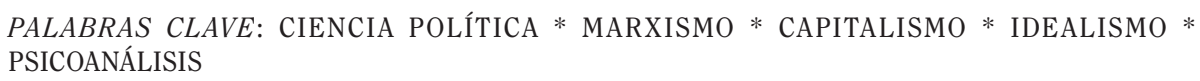

\section{ABSTRACT}

This article analyzes, in the context of the current systemic and financial crisis and the deepening of neoliberal policies, the proposal of several thinkers (Bosteels, Dean, Badiou y Žižek) in relation to the idea of a communism linked to the Lacanian real. It is then set up that this new Lacanian communism evades the problems derived from the current crisis and from the resulting exacerbation of neoliberalism, and therefore it goes away from the Marxism with which it could be associated. In brief, the new Lacanian communism is a new philosophical idealism, which denies the anti-establishment political action and the social change.

KEYWORDS: POLITICAL SCIENCE * MARXISM * CAPITALISM * IDEALISM * PSYCHOANALYSIS

Profesional independiente en corrección de estilo.

royalfarov@gmail.com 


\section{INTRODUCCIÓN}

La política no es más que el discurso y la acción humanos enfocados en organizar la sociedad de una determinada manera. Por años, después de la caída del Muro de Berlín y del capitalismo burocrático soviético, el neoliberalismo se definió como la política en sí.

No obstante, el idilio neoliberal despertó de su sueño de opio, cuando la materialidad del mundo aplastó la virtualidad del parásito financiero. En el 2008, explosionó el triunfalismo burgués, dejando al desnudo al rey neoliberal, quien se creía arropado por las telas de la eternidad y la estabilidad. La burbuja financiera había invertido la realidad, pero pronto la estructura económica develó la escamoteada crisis sistémica y terminal, que yacía bajo el carnaval postmoderno de la différence.

Además, con alta tecnología y oscura corrupción, los seguidores del neoliberalismo han tratado de mantenerlo con vida artificial. La política ha devenido, sin más remedio, una cuestión casi de santería, de brujería; acabar con el capitalismo zombie es la tarea. Sobre los restos del rey neoliberal, se alzan las voces contestatarias y algunas no tanto.

En la academia, la izquierda retoma poco a poco el espacio que el rey había usurpado. Sin embargo, intelectuales que por el postmodernismo se habían decantado por la culpa de haber abrazado en su momento la Modernidad y que se habían transfigurado en anti-marxistas; hoy se llaman a sí mismos: marxistas. A estos se les ha denominado el nuevo comunismo lacaniano (NCL).

Así, lo que se va a intentar probar es que el NcL más que ser un punto de reflexión y de articulación de la acción política, en el contexto de la actual crisis capitalista y de la consecuente exacerbación de las políticas neoliberales; es un discurso abstraído que niega el carácter concreto de la problemática que se está enfrentando (pobreza y desvío de fondos públicos a lo privado) a través de divagaciones especulativas e idealistas de corte lacaniano, que dificultan o impiden asumir una acción política contestataria y transformadora, que supere la realidad presente mediante la unidad de teoría y práctica.
Para llevar a cabo la prueba de esta tesis, es preciso: a) caracterizar el contexto del actual capitalismo; b) definir qué es el NCL; c) señalar las deficiencias del NcL y d) establecer algunos parámetros que permitan reflexionar y diseñar estrategias políticas contra el sistema capitalista $y$ las políticas neoliberales.

\section{EL ACTUAL CONTEXTO CAPITALISTA}

Existen cuatro aspectos que definen el capitalismo actual. El primero es la crisis sistémica iniciada en los años 70 del siglo pasado. El segundo es un reacomodo del poder, que pasa de Estados Unidos a China. El tercero es la exacerbación del neoliberalismo; todo lo cual engendra el cuarto elemento, su antítesis, el nuevo auge de la izquierda.

La crisis sistémica del capitalismo, como elemento fundamental de este, inició después de la Edad de Oro del capitalismo (entre finales de la Segunda Guerra Mundial y los años 70 del siglo xx), caracterizada por un rápido desarrollo (Quiggin, 2010 y Alfaro, 2011). Así, a partir de los 70, se experimenta una acelerada inflación y un alto desempleo (Quiggin, 2010), que se ha manifestado en una caída en los ingresos de la clase media estadounidense, cuyo fenómeno ya en el siglo xxI, se ha extendido a la mayoría de las grandes economías occidentales (Freeland, 2012).

Con la caída de la tasa global de ganancia (Harvey, 2010), se crea el proyecto neoliberal que enfatiza producir los medios para acumular capital y mantener el orden social, haciendo pasar sus intereses particulares por el bien común (Apeldoorn y Overbeek, 2012), conllevando el control sobre la plusvalía del Estado a lo privado (Harvey, 2012).

Este proyecto ha tenido un nombre: globalización, la cual ha implicado "la desjerarquización y descentralización de los negocios y la flexibilización de la producción y el proceso de trabajo" (Fisher, 2010: 3) ${ }^{1}$. La globalización es la última expansión del capital a todos los más recónditos lugares del planeta, con lo cual y sin oposición desde la caída del Muro de Berlín, ha

$1 \quad$ Esta y las siguientes traducciones de textos en lengua no española incluidos en la bibliografía, son propias. 
servido "para naturalizar el capitalismo" (Cazdyn y Szeman, 2011: 1). La globalización ha sido entonces, en lo referente al neoliberalismo económico, apertura comercial y liberalización de mercados (Quiggin, 2010). En lo ideológico, el énfasis ha estado "sobre el individualismo, lo material, el consumo y la adquisición personal" (Smyth, 2011: 3). Así, el neoliberalismo "ve cada sector de la sociedad sujeto a la lógica de la producción, mercantilización, competición y del análisis de costo-beneficio" (Apple, 2013: 6).

En la visión neoliberal, "el capitalismo es un sistema abierto $y$, por ende, bueno, aquel del mercado" (Jameson, 2011: 146) 2 . De hecho, en este sentido, "el capitalismo no es en lo absoluto acerca del desarrollo humano" (Lebowitz, 2010: 16), idea que completa Heinrich (2012: 87) al decir que "el objetivo de la producción capitalista es la plusvalía y no la satisfacción de las necesidades".

En síntesis, la globalización y la ideología neoliberal son una reacción a la crisis sistémica iniciada en los años 70 del siglo xx. El fin es elevar nuevamente la tasa global de ganancia, para lo cual se estableció el capitalismo financiero, que buscando huir de los improvistos y oscilaciones de la economía real, creo un sistema financiero para acelerar la circulaciónreproducción del capital, lo cual falló con la recordada explosión de la burbuja hipotecaria (Alfaro, 2011) y con lo que se "ha acelerado la emergencia de China como un gran poder" (Garnaut, 2009: 1).

Con la crisis de 2008, China vino al rescate y mantenimiento de la economía (Overbeek, 2012 y Sanderson y Forsythe, 2013). El instrumento que ha posicionado a China tan fuertemente es el Banco Chino de Desarro-

2 Los sistemas abiertos implican una interacción con el ambiente externo, a través del cual el sistema se hace entrópico. Mas, el sistema capitalista de Jameson es un sistema abierto, que es negentrópico, o sea, se fundamenta en una entropía negativa que evita que el sistema se deteriore y desaparezca. El problema es que los sistemas abiertos negentrópicos no existen y el sistema capitalista requiere algo fuera de sí para metabolizarlo, pero el mundo le pone un límite material a tal expansión. Además, si el sistema come, también crea desechos y sustancias nocivas para él mismo, luego se deteriora y muere. llo (China Development Bank), a través del cual "China está ahora prestando más a los países en desarrollo que el Banco Mundial" (Sanderson y Forsythe, 2013: 103). Así, China ha creado alianzas económicas con Venezuela, Ecuador, Etiopía, Egipto, Argelia, Nigeria, entre otros (Sanderson y Forsythe, 2013), dentro de un panorama global caracterizado por la no-evidencia del desarrollo de una hegemonía china militarizada alejada del estilo de Stalin o Brezhnev (White, 2009) y de la costumbre estadounidense de usar las armas para digerir sus problemas de producción $y$ demanda (Wang y Gang, 2009). Asimismo y unido al rol del Banco Chino de Desarrollo, el yuan está comenzando a desplazar el dólar americano en el comercio y a operar una depreciación de este (Sanderson y Forsythe, 2013), por lo que la reacción en Estados Unidos y Europa no se ha hecho esperar. Esta reacción ha venido siendo la exacerbación del neoliberalismo.

Las grandes burguesías de Europa y Estados Unidos, en el proceso de negarse a perder sus posiciones hegemónicas con respecto a China, persisten en que solo una versión más fuerte del neoliberalismo es la vía para la prosperidad (Antonio, 2012) o sea, la desregulación financiera, pilar de la ideología neoliberal, continúa trabajando (Hager, 2012), con lo cual se busca alcanzar que el neoliberalismo siga "dominando política y culturalmente" (Antonio, 2012: 583).

Ahora bien, si es cierto que el neoliberalismo de Ronald Reagan y Margaret Thatcher, en los años 80 del siglo xx, estuvo embebido de un supuesto aire posmoderno de expansión democrática, mediante el rescate de la différence, por lo menos a nivel discursivo; también es verdad que el neoliberalismo del siglo xxi se define por "el espectro de la barbarie" (Lebowitz, 2010: 7). En otras palabras, "el peligro más claro y presente del capitalismo contemporáneo es la tendencia a suspender la democracia [burguesa]" (Žižek, 2012a: 15). En otras palabras, por un lado hay una tendencia a suspender los derechos civiles y por otra parte, se está operando una fuerte presión sobre las ramas del conocimiento ligado a las humanidades $y$ las ciencias sociales. 
En relación con los derechos civiles, estos se han reducido cada vez más al derecho al voto, para mantener la democracia formal, aunque a nivel del contenido no se pueda ni protestar. Se ha observado a la policía golpeando o matando a protestantes en Estados Unidos, Francia, México, Grecia, España, Costa Rica, etc. En consecuencia, la supuesta democracia burguesa ha devenido una plutocracia; así "el capitalismo es simplemente el poder social de un 'honorable' crimen organizado" (Badiou, 2012: 26), cuyo objetivo es la conducción - por parte de esta élite plutocrática-del Estado (Freeland, 2012).

Con respecto al conocimiento, este que "es una subjetividad comúnmente compartida que puede reproducirse sin importar cuáles individuos concretos lo comparten" (Carchedi, 2011: 203), se ve sometido a la abierta privatización (leyes de copyright o la ley sopa) o a la banalización del producto de algunas áreas del saber humano, para que sea de acceso a la gran masa consumista. Ejemplo de esto es la ideología post-postmoderna, que se podría decir es la lógica cultural del Tea Party, una hermenéutica entendida como un "más intenso modo de producción/consumo" (Nealon, 2012: 51-52), dentro de la homología "entre la lógica cultural de la globalización y la lógica económica del capital financiero" (Nealon, 2012: 32). Esto plantea para las humanidades y las ciencias sociales, la obligatoriedad de intensificar el postmodernismo y el consumismo de la diferencia ligada a tal postmodernismo (Nealon, 2012).

El post-postmodernismo se enfoca "en los poderes de lo falso de la literatura, sus post-postmodernas habilidades para crear otros, virtuales mundos" (Nealon, 2012: 158). Luego, las humanidades $y$ las ciencias sociales se trivializan en la forma de relatos o de paraciencias, que como libros de barata autoayuda, son consumidos por la masa, sin necesidad alguna de algún manejo técnico y cognoscitivo. Las ciencias no-duras (humanidades $y$ ciencias sociales) se convierten en literatura y así, el verdadero conocimiento filosófico, lingüístico-literario, psicológico, etc., deviene en algo esotérico e inofensivo, lejos de la masa explotada y al servicio de una plutocracia corrupta $y$ deshumanizada, donde no se puede reconocer ningún prójimo, sino al victimario.
En resumen, nuestro panorama actual está marcado por una crisis sistémica iniciada en los años 70, que obligó a crear el proyecto neoliberal y el capitalismo financiero, este último explotó con la burbuja inmobiliaria, cambiando las cuotas de poder en el concierto de las naciones y que ha puesto a China como director de orquesta, lo cual ha hecho reaccionar a la gran burguesía plutocrática estadounidense y europea con una intensificación no-democrático burguesa $y$ neoliberal, que tiene como fin reimpulsar el capitalismo de tales regiones y evitar cualquier reacción contestataria, lo cual incluye una privatización-banalización del conocimiento.

Como se mencionó anteriormente, esto engendra su propia antítesis, manifestada en protestas callejeras $y$ en un nuevo auge de la izquierda. Pero, como no todo lo que brilla es oro, no todo aquello que se nos vende como izquierda, lo es.

\section{EL NCL: CARACTERÍSTICAS Y DEFICIENCIAS}

Un concepto tan abarcante como el de NCL implica no caer en una falacia de división, ni en una de composición. Evidentemente, de manera particular, se puede encontrar en casi todos los autores que seguidamente se analizaran, alguno que otro elemento rescatable, pero no por eso la propuesta general lo es. Es decir, el hecho de que la propuesta general sea valorada negativamente, no implica que hayan elementos particulares necesarios para la asunción teórico-práctica de la superación del capitalismo.

Asimismo, se indica al lector que se ha utilizado el término comunismo en lugar de socialismo, ya que se discuten autores del ámbito europeo en lengua inglesa, donde el término socialismo refiere más a lo que nosotros entendemos como socialdemocracia $y$ en Estados Unidos, como liberales.

Entrando en materia, Hobsbawn indicaba en su momento que "el Marx del siglo veintiuno será casi seguramente muy diferente del Marx del veinte" (2011: 6). Para Bosteels (2011), Žižek (2012a y 2012b), Badiou (2012) y Dean (2012), lo es. 
El marxismo del siglo xxi se topa con un mundo globalizado, donde la tecnología se ha desarrollado a tal grado que verdaderamente, la jornada laboral podría reducirse drásticamente y como efecto negativo del desarrollo capitalista, el planeta está al borde del irreversible desastre ecológico y más de 1000 millones de personas (conservadoramente hablando) no tienen qué comer; a diferencia del marxismo del siglo $\mathrm{xx}$, el cual sucumbió ante el empuje leninista que llevó a la Unión Soviética a entrar en un "socialismo", sin el suficiente desarrollo de las fuerzas productivas; de ahí que Stalin tuvo que emprender un proceso de acumulación primitiva, para poder industrializar la Unión Soviética.

Se creó así el monstruo del "socialismo real" o sea, una estructura discursivamente marxista, dentro de una particular interpretación leninisto-estalinista y económicamente capitalista (disfuncional, pero capitalista). Sin embargo, a pesar de las diferencias contextuales entre ambos marxismos, la estructura teórica y lógica del marxismo como un todo y del método dialéctico (en tanto factor fundamental del marxismo) permanece. Es decir, el empleo del marxismo no como simple doctrina política, sino como ciencia implica el abordar el problema del capitalismo actual como elemento concreto, con el fin de determinar el diagnóstico y comprensión de lo que sucede, así como lograr su transformación; mas es aquí donde el ncL pierde su carácter práctico, para perderse en divagaciones petites buorgeoises.

Se iniciará con Bosteels, quien plantea dirigirse hacia la verdadera realidad del comunismo (the actuality of communism): "en un sentido que no es ni una continuación dogmática de la política partidaria, como la conocemos, ni un especulativo sueño filosófico" (2011: 9). En otras palabras, Bosteels entiende la verdadera realidad del comunismo, como un proceso en el cual se da "la necesidad de un retorno a la ontología" (2011: 40). Así, este giro ontológico (ontological turn $)^{3}$ trata de darle un fundamento a la verdadera realidad del comunismo, en cuanto esta verdadera realidad (actuality):

3 El giro ontológico parece poner distancia con el giro lingüístico del postmodernismo; sin embargo, como se verá, la propuesta de Bosteels parece desmentir esto. ...presupone la inmanencia de pensamiento y existencia, yendo tan lejos como para aceptar la maligna identidad de lo racional y lo real, no como algo dado dogmáticamente, garantizado por el curso objetivo de la historia, sino como una tarea abierta $y$ en proceso para la política (2011: 39). [En palabras más simples, es] el repetido inicio de un necesario empuje (drive) hacia una continuada emancipación (2011: 23).

La propuesta de Bosteels, en síntesis, indica que se debe "percibir el comunismo (...) como algo que está siempre ya aquí" (2011: 39), algo que "debe ser también hecho real (actualized) y organizado como el movimiento real que elimina el presente estado de cosas" (2011: 239). Entonces, el comunismo que siempre está con nosotros, según Bosteels, en tanto Idea-Evento -lo cual implica fuerte influencia de Badiou y Žižek - solo requiere "encontrar la inscripción en un cuerpo concreto, la carne colectiva y el pensamiento de una subjetividad política internacionalista" (2011: 239). O sea, el panorama actual se resuelve, de manera idealista (en el sentido filosófico del término), cuando la idea comunismo interpele a un sujeto político internacionalista. Al mejor estilo althusseriano y con un aire lacaniano (seguramente heredado de Badiou y Žižek), el comunismo de Bosteels es una simple interpelación ideológica, colocada al lado de la historia. Posteriormente, Bosteels se aleja totalmente de Marx, de la dialéctica $y$ de cualquier relación racional con la realidad, con la materialidad.

Dean (2012), por su parte y según sus propias palabras, comparte con Bosteels $y$ Žižek la necesidad por un partido, el cual "es un sistema adaptable y complejo" (Dean, 2012: 20). De hecho, Dean afirma que la finalidad del partido "es la revolución proletaria, es decir, la destrucción del sistema capitalista de explotación y expropiación, de proletarianización, y la creación de un modo de producción donde el libre desarrollo de cada uno es compatible con el libre desarrollo de todos" (2012: 20). Para realizar este bello ideal, el partido tendría que hacerse de lo que Dean llama "el horizonte 
comunista", en el cual la palabra horizonte designa "una dimensión de la experiencia que nosotros no podemos nunca perder... El horizonte es Real en el sentido de imposible - no podemos nunca alcanzarlo-y en sentido de existente (actual)" (Dean, 2012: 1-2). O sea, el horizonte es lo Real lacaniano.

Así, Dean siguiendo a Lacan (con una fuerte influencia žižekiana) asume que el horizonte es imposible en cuanto se aleja de lo Simbólico lacaniano, en otras palabras, no es parte del contexto cultural actual. Para usar un término muy postmoderno, el comunismo es lo innombrable $y$ si no se puede nombrar, no tiene existencia o más bien, tendría una existencia suplementaria, un punto frontera entre la cultura y la nada. No obstante, es existente (actual), según Dean, en tanto es esa misma suplementariedad, la cual no se puede nombrar $y$ por ende, tampoco pensar. De ahí que el horizonte comunista esté basado no en lo racional, sino en el deseo y en consecuencia: "el deseo comunista es un deseo por la colectividad" (Dean, 2012: 197); asimismo, "la colectividad es la forma del deseo en dos sentidos: nuestro deseo y nuestro deseo por nosotros; o el deseo comunista es el deseo colectivo por el desear colectivo" (Dean, 2012: 199).

El horizonte comunista de Dean parece resolverse en una petitio principii, una falacia de circularidad, que en sus términos lacanianos rompería con lo racional-simbólico, con lo cual Dean no solo sigue el irracionalismo postmoderno, sino que sume la acción política en la experiencia individual: "el comunismo está subordinado a una decisión individual por él" (Dean, 2012: 195) y por lo tanto, de fondo anula la posibilidad siquiera de plantearse el comunismo, por cuanto esto requeriría un acto comunicativo, a saber, simbólico; lo cual dentro del marco lacaniano de lo Real asumido por Dean, sería insertarse en la represión homogenizante de la cultura. En síntesis, el horizonte comunista de Dean es un proceso identitario suplementario, "una dimensión de la experiencia" (Dean, 2012: 1). Por eso, se hace difícil comprender el mecanismo que emplea Dean para plantear el proletariado como "la clase universal, el sujeto-objeto de la historia" (2012: 72), cuando el mismo Dean parece concebirlo como un aglutinamiento eventual de identidades ${ }^{4}$, que solo adquiere forma organizada a través del partido $y$ consecuentemente, al mejor estilo de las vanguardias leninistas, crea una élite que guía y dirige, a esa masa aglutinada.

Para Badiou, en otro orden de cosas, "el capitalismo contemporáneo posee todas las características del capitalismo clásico" (2012: $11)$, con la presencia de "los apetitos financieros de una minúscula oligarquía" (2012: 12), que convierte el capitalismo en "el poder de un "honorable' crimen organizado” (2012: 26).

En oposición a este marco capitalista, Badiou propone retomar el marxismo como "el conocimiento organizado de los medios políticos requeridos para deshacer la sociedad existente $y$, finalmente, realizar una figura racional igualitaria, de organización colectiva para la cual el nombre es "comunismo"' (2012: 8-9). En ese sentido, Badiou ve el marxismo como el aglutinante o la expresión de la Idea (en sentido badiouiano), que permite llevar a una exacerbación revolucionaria, los disturbios que la actual crisis capitalista ha desatado en diferentes lugares $y$ movimientos (la Primavera Árabe, Occupy Wall Street, los Indignados, entre otros), que expresarían la virtual Idea, encarnando esta "en los individuos que la 'expresan”' (Žižek, 2012b: 216).

Así, el Evento, "un quiebre o ruptura con el orden de las cosas" (El-Ojeili, 2012: 90), debe encontrar su prolongación en la organización, la cual es "la transformación del poder eventual dentro de la temporalidad" (Badiou, 2012: 70). Dicho de otra manera, la verdad que ha provocado los disturbios mencionados anteriormente, producto de la crisis financiera $y$ el despotismo, debe - siguiendo la idea de Badiou- tomar forma en y por la organización. Pero (Badiou siguendo a Lacan) la organización "refiere a una mediación entre el deseo y la ley cuyo nombre es: el Sujeto" (Badiou, 2012: 66). O sea, la organización es el establecer el evento como fuente de interpelación ideológica, que deriva en producir un sujeto, a saber, es la Idea

$4 \quad$ Esto es la noción badiouiana "del genérico poder de lo múltiple" (Badiou, 2012: 85), donde "la realidad es la multiplicidad de multiplicidades" (Žižek, 2012b: 741). 
badiouiana, entendida como "la subjetivación de un interjuego entre la singularidad de un proceso de verdad y una representación de la Historia" (Badiou, 2010: 3). Entonces, el sujeto en sí solo es, en cuanto la Idea y la organización, como materialización de la primera, lo interpela. La Idea tiene luego, para Badiou, "el genérico poder de lo múltiple" (2012: 85), en tanto cada proceso particular no se anula, sino que es abordado dentro del evento como una situación que localiza, intensifica y contrae las diversas identidades.

Por ende, no son las condiciones materiales del actual capitalismo decadente las que exactamente llevan a la organización contestataria. Pero esto, recordando de fondo también a Althusser, huele a un idealismo filosófico, el cual Badiou trata de solventar de la siguiente manera: "que el valor histórico de la Idea es primero que todo atestiguado por el disturbio, es cierto. Que el valor político del disturbio es atestiguado por la organización que es fiel a él, y es fiel a él porque por él el disturbio afirma la Idea, no es menos cierto" (2012: 63).

Sin embargo, esto lleva a una falacia de circularidad, que sume la propuesta de Badiou en el ahistoricismo y en consecuencia, en la inacción política, ya que no se puede actuar fuera de la historia. Lo que realmente significa esto, es que, Badiou señala que la Idea se manifiesta (o atestigua) en el disturbio, con lo que el segundo es efecto del primer concepto. A la vez, el disturbio se manifiesta en la organización, en cuanto a su valor político, el cual afirma la Idea. Entonces, la Idea es al mismo tiempo causa y efecto del disturbio-organización y así no puede haber acción recíproca entre ambos puntos de esta ecuación.

La posición de Badiou es propia de una elucubración sometida a los requerimientos del intelectualismo francés ${ }^{5}$, que tiende a confundir el hecho de expresar las cosas complicada $y$ oscuramente, con la idea de pensar profunda $y$ racionalmente.

5 De hecho, "el pensamiento francés se ha desarrollado en un modo altamente no-relacional de pensar y ha completamente carecido de una explicación de la racionalidad mediada y mundana" (James, 2012: 7); dicho esto de manera más elegante.
Para finalizar con el análisis de los diferentes autores, vamos ahora con Žižek. Este autor ofrece tres características, del capitalismo contemporáneo, para él fundamentales, a saber: una prevalencia de la renta sobre los beneficios, un aumento en la incidencia estructural del desempleo y la aparición de una burguesía asalariada (Žižek, 2012a), lo cual definiría el capitalismo "como una formación social [que] está caracterizada por un desbalance estructural" (Žižek, 2012a: 8), donde "la principal característica del capitalismo contemporáneo no es solo la hegemonía, sino también la [relativa] autonomía del capital financiero" (Žižek, 2012b: 247), sin olvidar que "el capitalismo está estructuralmente siempre en crisis" (ibid.: 651).

De igual modo, en el marco de la actual crisis, indica Žižek que "el sistema capitalista mismo no es más capaz de encontrar un nivel inmanente de estabilidad auto-regulada" (2012a: 12-13) y que además, existe "la tendencia a suspender la democracia" (ibid.: 15) y a convertirse, mediante la globalización, en algo supracultural; es decir, "la lección fundamental de la globalización es precisamente que el capitalismo puede acomodarse a todas las civilizaciones" (ibid.: 55).

Hasta aquí, en términos generales, Žižek percibe adecuadamente el contexto capitalista actual. Los problemas con su propuesta comienzan a ser patentes, cuando él deshistoriza la actual crisis financiera al circunscribirla exclusivamente "al excesivo gasto y préstamos estatales" (Žižek, 2012a: 23). Con esto de la causa de la crisis financiera, este autor elimina la continuidad del proceso histórico. Si el tiempo histórico se pensara como una recta conformada por diferentes y consecutivos puntos, donde la recta como un todo fuera la continuidad del espacio-tiempo; entonces para él solo existirían los puntos de tal recta, diferentes pero no-secuenciales ni consecutivos, o sea, como discontinuidad.

Para fundamentar esta discontinuidad, Žižek (2012a) toma del francés dos palabras que se traducen en inglés como "future". Las palabras francesas son futur y avenir. En español podrían traducirse futur como futuro y avenir como porvenir, pero aún así no corresponderían 
al significado en lengua francesa. Así, futur implica la realización de las tendencias existentes en el presente, o sea, habría un proceso de continuidad a partir de un punto discontinuo, esto es, el presente.

La palabra avenir, al contrario, conlleva una ruptura con el presente, por lo que más que continuidad se daría alguna clase de salto cualitativo y por ende, no habría recta, sino solo puntos inconexos: "una discontinuidad con el presente" (Žižek, 2012a: 134). De ahí que lo que Žižek pretende es "repetir 'la crítica de la economía política' marxista sin la noción utópica-ideológica de comunismo" (2012b: 257). Pero, al no poder plantear un "hacia dónde", un posible, la acción deviene ciega y Žižek (2012b) cae en alguna forma de nihilismo que lo lleva a dudar de movimientos como Wall Street y a la vez, de la idea de un partido político: "el rol movilizante de los movimientos y partidos no es suficiente: el hueco que separa la gente misma de las formas organizadas de agencia política tiene que ser de algún modo superado pero ¿cómo?” (Žižek, 2012b: 1000). Más esto no tiene solución dentro del esquema žižekiano, ya que él diluye cualquier visión política de alcances generales, en decisiones éticas particulares (Žižek, 2012b). En consecuencia, "la idea de que uno puede fundamentar la política en la ética o que la política es en última instancia un esfuerzo estratégico para realizar posiciones éticas de antemano, es una versión del "gran Otro" (Žižek, 2012b: 963). A saber, la política, para Žižek, se cierra en una visión postmodernista que rechaza lo general.

Aunado a lo anterior, Žižek separa la teoría de la práctica dentro del proceso históricopolítico. Al respecto dice: "enfrentado con las demandas de los protestantes, los intelectuales no están definitivamente en la posición de los sujetos que se supone saben: ellos no pueden operacionalizar estas demandas o traducirlas en propuestas para medidas precisas y realistas" (2012b: 1007).

En esta separación, también enfatiza la experiencia particular como límite para el pensamiento teórico. En este marco, la conciencia revolucionaria del proletariado, para Žižek, "es "parcial"' (2012a: 4).
Todas estas separaciones entre lo particular y lo general, la teoría y la práctica, llevan a Žižek a refugiarse en lo Real lacaniano, para retomar:

...la diferencia lacaniana entre la realidad y lo Real: el primero es la realidad social de la gente existente (actual) envuelta en la interacción y en el proceso productivo, mientras lo Real es la inexorable, 'abstraída', lógica espectral del Capital que determina lo que ocurre en la realidad social (Žižek, 2012a: 102). Žižek:

Dicho de otra manera por el mismo

...esto Real, sin embargo, no es la Cosa inaccesible, sino el hueco que previene nuestro acceso a ella, la 'roca' del antagonismo que distorsiona nuestra visión del objeto percibido a través de una perspectiva parcial. Así, la 'verdad' no es el estado 'real' de las cosas, accediendo por una visión 'directa' del objeto sin ninguna distorsión en la perspectiva, sino lo muy Real del antagonismo que causa la distorsión misma en la perspectiva (Žižek, 2012b: 47-48).

Lo Real es lo que -con términos de la deconstrucción- suplementaría la realidad, es decir, lo Real es el producto de los fallos de la simbolización (Lacan, 1972) y en tanto, lo Simbólico requiere de un suplemento; entonces, la verdad entendida como una relación entre Ser y Pensamiento (lenguaje) siempre sería parcial, ya que en tal relación siempre habría una falta, lo que la suplementa; asimismo, la realidad a la cual responde la noción clásica de verdad, definida como la correspondencia entre la realidad y el discurso sobre esta.

¿Cuál es el procedimiento para asumir entonces el capitalismo desde la noción de lo Real lacaniano? Žižek aborda el capitalismo, a través de lo Real, del siguiente modo: primero él dice que lo Real es "el hueco que previene nuestro acceso a ella [a la cosa]" (Žižek, 2012b: 48); para, en segundo lugar, decir que: 
Este hueco es tangible en el modo que la situación económica de un país puede ser considerado buena y estable por los expertos financieros internacionales, aún cuando la mayoría de su gente esté peor que antes - la realidad no importa, lo que importa es la situación del capital (Žižek, 2012b: 244).

Entonces una de dos: el capitalismo es inaccesible en su fundamento, debido a que el ámbito simbólico de los expertos internacionales neoliberales (adjetivo final olvidado raramente por Žižek) escamotea esta lógica subyacente de reproducción y circulación del capital, al modo de la caja negra de los gestálti$\cos y$ por ende, no se puede conocer su realidad $y$ en consecuencia, es lo Real; o segundo, lo Real solamente es una maraña ideológica que busca ocultar las causas reales y materiales de la crisis sistémica capitalista.

Lo cierto es que, como se observó al inicio del análisis sobre Žižek, él tiene una adecuada comprensión de lo que sucede en el capitalismo contemporáneo. Así, a pesar de que Žižek (2012a y 2012b) se declara marxista, su propuesta no pasa de ser un idealismo filosófico, embebido en una metafísica de lo Real. El discurso de Žižek responde "a un juego ideológico propio de la posmodernidad" (Alfaro, 2009: 27), "es pura verborrea" (Alfaro, 2009: 20), el efecto mercadotécnico de la actual y desesperada burguesía transnacional.

\section{LA SUPERACIÓN DEL NCL}

El ncl asume el capitalismo como una expresión de lo Simbólico lacaniano, como un elemento represor y en último caso lingüístico $y$ con un énfasis fragmentante, en relación con lo Imaginario, y totalizante en función de que lo Simbólico se percibe como un absoluto.

En este sentido, el capitalismo, en relación con el marco interpretativo-ideológico del NcL $y$ siguiendo fielmente a Lacan bajo la influencia de Žižek en la mayoría de casos, se representaría como una totalidad cerrada, totalitaria si se quiere; pero que en cuanto manifestación de lo Simbólico siempre estaría suplementada por lo Real lacaniano. Lo Real, entonces, en tanto se toma como aquello que no permite a lo Simbólico estar presente, sino diferido; lo Real se convierte en el espacio de la lucha de clases, mas es un espacio no-pensable, no articulable como código, ya que el código es lenguaje y el lenguaje es lo Simbólico, la cultura. Por ende, lo Real es la renuncia a la lucha de clases (en la realidad). Así, a pesar de que Dean (2012), Badiou (2012), Bosteels (2011) y Žižek (2012a y 2012b) reconocen la problemática alrededor del capitalismo actual, su contexto de extrapolación de la explotación mediante el desvío de dinero público al sector privado, el NCL desplaza y condensa esta problemática en la versión lacaniana de la caja negra de la psicología Gestalt, o sea, lo Real.

Con todo esto, el ncL renuncia no solo a la superación del capitalismo en comunismo, sino que incluso niega la materialidad, la realidad $y$ se suma en el giro lingüístico posmoderno, que cree que el lenguaje "constituye, más que refleja, el mundo" (Bertens, 1995: 6). En consecuencia, el capitalismo, como se afirmó, no puede desde esta perspectiva ser pensado, sino solo experienciado, es un puro relato corporizado. Por este motivo, la acción política deviene discontinuidad, desconexión entre teoría y práctica, énfasis sobre lo particular y negación de las realidades utópicas, a favor de la ilusión utópica (Utopianism en inglés) de lo Real.

Entonces, ¿cuáles deben ser los cambios que permitan superar el NcL? La respuesta está contenida en el mismo ncL. Si el error del ncL es su bagaje lacaniano y especialmente, el pseudoconcepto de lo Real, el primer paso es negar lo Real. Esto deja, para seguir usando el lenguaje lacaniano (solo con el fin de no perder el hilo de la discusión y no por compartir el ideario de Lacan), con lo Simbólico, con vistas a despojarlo de todo el prejuicio que el lacanismo ha echado sobre él.

Si en el psicoanálisis freudiano, la etapa edípica, es la que permite introyectar la normativa moral de la cultura donde, por lo menos en Occidente, el niño encuentra la asunción de los roles generales y biológicos de hombre $y$ mujer, entonces en un inicio se podría argumentar que a través de la fase edípica, el niño se inserta en el principio de realidad, en cuanto el principio de placer quedaría sometido a los imperativos sociales. 
El principio de realidad así entendido evidentemente tiene un carácter represivo, porque no toda realidad puede ajustarse a tal principio $y$ en cuanto, también la realidad social es entrópica como cualquier otro sistema natural. Esta es la interpretación que yace en el enfoque lacaniano sobre Freud y que toma cuerpo en el concepto de lo Simbólico lacaniano.

Sin embargo, el psicoanálisis lacaniano se equivoca en esta interpretación. Si bien, el principio de realidad incluye la fase edípica; también es cierto que implica el desarrollo de un Yo sólido, fuerte, que establezca el vínculo entre la realidad exterior y la realidad psíquica del individuo. Dicho de otra manera, el principio de realidad no es la supresión del deseo, sino la comprensión de este dentro de sus verdaderos alcances socio-biológicos. El Ello (el instinto sexual) podría querer satisfacción coital en todo momento y el Superyó, en determinados contextos, podría llegar a renunciar a la sexualidad por ser "pecaminosa", pero el instinto biológico de preservar la especie (lo que es al fin y al cabo el Ello, o sea, más que la simple satisfacción del deseo que es un simple medio) impulsa a la reproducción. Así, si el principio de realidad sucumbiera al principio de placer, no habría cuerpo que aguante un permanente, diario y eterno juego coital (es preciso recuperar la energía individual y social, hay que producir el alimento). La realidad biológica, material, pone límites al Ello, pero también al Superyó. Aunque una sociedad niegue el lesbianismo, las lesbianas existen. Mas, a pesar de que las lesbianas existen, el imperativo biológico de conservación de la especie también pone límites al lesbianismo. El principio de realidad, por ende, no se reduce al ámbito del Superyó, de la conciencia normativa, sino que implica las otras instancias freudianas, el Ello y el Yo. Luego, el principio de realidad es la dialéctica entre lo particular y lo general, a veces manda el imperativo personal del deseo, a veces el general de lo biológico-social.

El psicoanálisis lacaniano toma partido a favor de lo particular, con lo cual niega toda posibilidad de acción, cayendo en el nihilismo que Lacan llama lo Real.

Volviendo al capitalismo, este es realidad, es material; luego, no es solo una construcción simbólica, discursiva y por tanto, hay que asumir su transformación en términos activos y materiales (como unión de teoría y práctica). No se puede caer en la inoperancia del sujeto lacaniano.

Así, si el problema de fondo del capitalismo es la caída en la tasa global de ganancia (Harvey, 2010) y aparejado a esto, la dificultad cada vez más extrema de hacer efectiva la plusvalía en el proceso de circulación-reproducción del capital; se debe, entonces, enfocar en incrementar esta deficiencia. ¿De qué manera? Pasando del consumismo histérico a un consumo racional: comprando de acuerdo con el imperativo del valor de uso, más que con los del valor de cambio.

Es interesante rescatar que la nueva visión ideológica neoliberal, el post-postmodernismo, afirma lo contrario. Los post-postmodernos acentúan el valor de cambio, por eso, en el contexto de la crisis del capital financiero, buscan "encontrar nuevos mecanismos para seguir trabajando el dinero mismo" (Nealon, 2012: 32). Nealon enfatiza el valor de cambio, el consumismo, la circulación del dinero, la mercancía por la mercancía. Lo opuesto, entonces, de lo que salva al capital, lo acaba; $y$ en economías como las latinoamericanas, dependientes y subdesarrolladas, esto podría exacerbar y hacer completamente evidentes las contradicciones de la lucha de clases, ocultas bajo el consumismo y las diferencias identitarias.

Dentro de esta lógica de la derecha, "Wal-Mart patrocinó un programa de Walton Scholars. Gente vino de múltiples naciones americanas, por ejemplo, para aprender cómo integrar lo que ellos perciben como su mandamiento para servir y estimular sus comunidades con modelos empresariales cristianos" (Apple, 2013: 135). Las uniones entre empresas multinacionales estadounidenses y los grupos ultraconservadores cristianos, buscan convencer a la gente de que "la libertad es básicamente un concepto económico y no uno político, que tiene su base primaria en los trabajos no regulados del mercado, luego la acumulación privada de capital puede ser igualada al bien público" (Apple, 2013: 134). 
Asimismo, con respecto al conocimiento, es preciso recordar que "la privatización del conocimiento y la cultura debe ser prohibida" (Harvey, 2012: 163), ya que "el conocimiento tiene un contenido social, un contenido de clase" (Carchedi, 2011: 38) y por ende, para que opere como transformador social, debe este ser de acceso totalmente abierto a todos. Para efectuar esto, el Movimiento Anti-copyright es una buena herramienta de lucha, pero también se hace hasta más necesario la no-aceptación de las leyes de protección del copyright mismo, que aunque legales, son también ilegítimas y como bien saben los juristas, uno no debe acatar una norma ilegítima. Esto pondría también en problemas la efectivización de la plusvalía. Al respecto, es rescatable la acción del Friday Seminar (grupo de activistas, estudiantes, etc.) que conformó, en su momento, una "coalición para boicotear la Pepsi Cola y otras empresas estadounidenses" (Apple, 2013: 147).

De igual modo, la socialización del conocimiento pasa por comenzar a romper la diferencia entre el trabajo manual y el trabajo intelectual. El intelectual debe reinsertarse en la cotidianidad proletaria, en procesos de organización (como un partícipe más, pero aportando su conocimiento $y$ habilidades) de los grupos explotados, del proletariado o como lo llama Harvey (2012), del precariato. Si debe o no debe haber un partido, cada circunstancia lo dirá, lo que sí es cierto es que los actuales partidos de izquierda que participan de la democracia burguesa deben ser disueltos.

En otro ámbito, la izquierda debe recobrar el "derecho a la violencia". Las pseudo-izquierdas postmodernas (ecologistas, feministas, etc.) han visto la violencia bajo la lupa del consenso burgués electoral, oponiendo este a la idea de revolución (Alfaro y Cruz, 2010). La derecha neoliberal no abandonará sus posiciones por gusto, por consenso, entonces el bajarlos requerirá de presión.

Finalmente, es un imperativo, para una nueva izquierda, abandonar los principios gnoseológicos ligados a lo positivo (la fenomenología y el positivismo) y acceder a un conocimiento profundo del método dialéctico y cuya deficiencia caracterizó al leninismo y al estalinismo. En este sentido, es aleccionador el texto de Lebowitz (2012), The Contradictions of "Real Socialism", donde él intenta, entre otras cosas, mostrar la aplicación del método dialéctico, pero se equivoca al interpretar que lo concreto dentro de su análisis no es la situación actual del capitalismo mencionada, sino el inexistente socialismo ruso.

Se debe pensar el movimiento, no solo para explicarlo, sino para producirlo. La utopía no como meta acabada de una vez y por todas. La utopía como límite y sucesión.

\section{CONCLUSIÓN}

El ncL más que ser un punto de reflexión $y$ de articulación de la acción política, en el contexto de la actual crisis capitalista y de la consecuente exacerbación de las políticas neoliberales, es un discurso abstraído que niega el carácter concreto de la problemática que se está enfrentando (pobreza, desvío de fondos públicos a lo privado, etc.) a través de divagaciones especulativas e idealistas de corte lacaniano, que dificultan o impiden asumir una acción política contestataria y transformadora, que supere la realidad presente mediante la unidad de teoría y práctica.

El NcL termina siendo una estrategia mercadotécnica, fundada principalmente de Žižek y Badiou, que en momentos del nuevo auge de la izquierda marxista inserta una mercancía, el mismo ncL, en el panorama intelectual, con lo cual no solo se obtienen ganancias económicas, sino que lanzan un producto, que por el mecanismo de legitimación que privilegia a Žižek y Badiou (a pesar de su oscuridad e inconsistencias) es atractivo para los grupos tendientes, en nuestros países latinoamericanos, a seguir cualquier fad (moda pasajera). Con esto, aparte de lo económico, introducen un sesgo político y gnoseológico, que busca impedir la transformación social del statu quo.

El NCL está adscrito al intelectualismo francés, que ya hace tiempo se perdió entre las reminiscencias de la separación cartesiana de la res extensas y de la res cogitans, y además entre lo positivo de la filosofía de Comte. 


\section{BIBLIOGRAFÍA}

Alfaro Vargas, Roy. "El pensamiento de Slavoj Žižek". Revista de Filosofía y Teoría Política 40. 2009: 11-30.

Alfaro Vargas, Roy. "Capitalismo zombie. Contribución a la crítica del último capitalismo". Telos. Revista de Estudios Interdisciplinarios en Ciencias Sociales 3 (13). 2011: 285-296.

Alfaro Vargas, Roy y Cruz Rodríguez, Omar. "Teoría del conflicto social y posmodernidad". Revista de Ciencias Sociales 128-129 (II-III). 2010: 63-70.

Antonio, Robert J. "After neoliberalism. Wither capitalism?".The Wiley-Blackwell Companion to Sociology. G. Ritzer (ed.). Malden (ма), Oxford. Wiley-Blackwell, 2012: 567-587.

Apeldoorn, Bastiaan van y Overbeek, Henk. "Introduction: the life course of the neoliberal project and the global crisis". Neoliberalism in crisis. Henk Overbeek y Bastiaan van Apeldoorn (eds.). Hampshire. Palgrave Macmillan, 2012: 1-20

Apple, Michael W. Can education change society? Nueva York y Londres: Routledge, 2013.

Badiou, Alain. "The idea of communism". The idea of communism. Costas Douzinas y Slavoj Žižek (eds.). Londres y Nueva York. Verso, 2010: 1-14

Badiou, Alain. The rebirth of History. Traducido por G. Elliott. Londres y Nueva York: Verso, 2012.

Bertens, Hans. The idea of postmodern. A history. Londres y Nueva York: Routledge, 1995.

Bosteels, Bruno. The actuality of communism. Londres y Nueva York: Verso, 2011.

Carchedi, Guglielmo. Behind the crisis: Marx's dialectics of value and knowledge. Leiden $y$ Boston: Brill, 2011.

Cazdyn, Eric y Szeman, Imre. After globalization. Oxford: Wiley-Blackwell, 2011.

Dean, Jodi. The communist horizon. Londres y Nueva York: Verso, 2012.
El-Ojeili, Chamsy. Politics, social theory, utopia and the world-system. Arguments in Political Sociology. Hampshire: Palgrave, 2012.

Fisher, Eran. Media and new capitalism in the digital age. The spirit of networks. Nueva York: Palgrave MacMillan, 2010.

Freeland, Chrystia. Plutocrats. The rise of the new global super-rich and the fall of everyone else. Nueva York: The Penguin Press, 2012.

Garnaut, Ross. "China's place in a world in crisis". China's new place in a world in crisis, Ross Garnaut. Ligang Song $y$ Wing Thye Woo (eds.). Camberra, Australia. Australian National University - Anu Press, 2009: 1-14.

Hager, Sandy Brian. "Investment bank power and neoliberal regulation: from the volcker shock to the volcker rule". Neoliberalism in crisis. Henk Overbeek y Bastiaan van Apeldoorn (eds.). Hampshire. Palgrave Macmillan, 2012: 68-92.

Harvey, David. The enigma of capital and the crises of capitalism. Londres: Profile Books, 2010.

Harvey, David. Rebel cities. From the right to the city to the urban revolution. Londres $y$ Nueva York: Verso, 2012.

Heinrich, Michael. An introduction to the three volumes of Karl Marx's capital. Traducido por A. Locascio. Nueva York: Monthly Review Press, 2012.

Hobsbawm, Eric. How to change the world. Reflections on Marx and Marxism. New Haven y Londres: New Yale University Press, 2011.

James, Ian. The new French Philosophy. Cambridge (uк)-Malden (ма): Polity Press, 2012.

Jameson, Fredric. Representing capital: $a$ commentary on volume one. Nueva York y Londres: Verso, 2011.

Lacan, Jacques. Las formaciones del inconsciente. Buenos Aires: Nueva Visión, 1972.

Lebowitz, Michael A. The socialist alternative. Real human development. Nueva York: Monthly Review Press, 2010. 
Lebowitz, Michael A. The contradictions of "real socialism". The conductor and the conducted. Nueva York: Monthly Review Press, 2012.

Nealon, Jeffrey T. Post-postmodernism or, the cultural logic of just-in-time capitalism. Stanford: Stanford University Press, 2012.

Overbeek, Henk. "Sovereign wealth funds in the global political economy: the case of China". Neoliberalism in crisis. Henk Overbeek y Bastiaan van Apeldoorn (eds.). Hampshire. Palgrave Macmillan, 2012: 138-160

Quiggin, John. Zombie economics. How dead ideas still walk among us. Princeton: Princeton University Press, 2010.

Sanderson, Henry y Forsythe, Michael. China's superbank. debt, oil and influence-How China development bank is rewriting the rules of finance. Singapur: Bloomberg Press (Wiley), 2013.

Smyth, John. Critical pedagogy for social justice. Nueva York: Continuum, 2011.
Wang, Xialou y Gang, Fan. "Economic crisis, Keynesianism and structural imbalance in China”. China's new place in a world in crisis. Ross Garnaut, Ligang Song $y$ Wing Thye Woo (eds.). Canberra, Australia. Australian National University - anu Press, Canberra, 2009: 137-153.

White, Hugh. "The geo-strategic implications of China's growth". China's new place in a world in crisis. Ross Garnaut, Ligang Song $y$ Wing Thye Woo (eds.). Canberra, Australia: Australian National University - anu Press. Canberra, 2009: 89-102.

Žižek, Slavoj. The year of dreaming dangerously. Londres y Nueva York: Verso, 2012a.

Žižek, Slavoj. Less than nothing. Hegel and the shadow of dialectical materialism. Londres y Nueva York: Verso, 2012b.

Fecha de ingreso: 16/02/2013 Fecha de aprobación: 11/12/2013 
